\title{
A VIDA DE AUGUSTO, DE NICOLAU DE DAMASCO: TRADUÇÃO ACOMPANHADA DE BREVE INTRODUÇÃO
}

Sandra Lúcia Rodrigues da Rocha*

* Universidade de Brasília sandralu@unb.br

RESUMO: A Vida de Augusto, de Nicolau de Damasco (séc. I a.C.), é uma das mais antigas biografias de um rei na tradição helenística. Seu valor como fonte para o estudo do gênero bios impõe-se por si só. Neste trabalho, apresento uma breve introdução à primeira metade da obra em sua atual forma fragmentária, assim como uma tradução dos respectivos fragmentos para o Português.

PALAVRAS-CHAVE: biografia antiga; Vida de Augusto; Nicolau de Damasco.

\section{NICOLAUS OF DAMASCUS' LIFE OF AUGUSTUS: SHORT INTRODUCTION AND TRANSLATION}

ABSTRACT: Nicolaus of Damascus' Life of Augustus (sec. I $\mathrm{BC}$ ) is one of the most ancient biographies of a king in the Hellenistic tradition. Its value as a source for the study of the genre bios stands by itself. In this work, I present a short introduction to the first half of the work in its present fragmentary form as well as a translation of the respective fragments into Portuguese.

KEYWORDS: ancient biography; Life of Augustus; Nicolaus of Damascus. 
1. Cf. HALL, 1923, p. iii.

2. Encontra-se apenas um problema de continuidade na passagem do capítulo 12 para o 13 (entre o final do fragmento 127 e início do 128), em que realmente há prejuízo do sentido, por se tratar de lacuna grande entre os dois fragmentos.

3. Isso se percebe também pela longa extensão do fragmento 127 , que contém os capítulos de 3 a 12 .

4. HALL, 1923, p. 81 (15, nota 2$)$.

5. Em geral, Nicolau utiliza Kâ̂sar (César) para referir-se tanto a Otávio Augusto, quanto a Júlio César, pressupondo, de certo modo, que o leitor saberá distinguir se está a falar de um ou de outro. Apenas em poucas ocasióes, trata Augusto como "o jovem César” - o que deve ter inspirado o compilador de Constantino a delimitar sua seleção do texto de Nicolau com essa expressão. $\mathrm{Na}$ tradução, mantivemos a expressão "o jovem César” para designar Augusto quando em Grego se encontrou néos Kaîsar; nas demais ocorrências indistintas de Kaîsar, para evitar ambiguidade, utilizamos em Português "Augusto" para um e "César" somente para o outro, Júlio César.
A tradução parcial aqui apresentada da Vida de $A$ Augusto, de Nicolau de Damasco, baseia-se nos fragmentos reunidos por Felix Jacoby (FGrHist 90) sob os números de 125 a 129. A obra completa inclui o fragmento 130, que contém, só ele, dezesseis capítulos; ao todo, é constituída de trinta e um capítulos. Os capítulos de 1 a 15, a seguir traduzidos, provêm todos de uma única fonte - o Codex Turensis - e abordam a infância e os primeiros anos da juventude de Augusto.Trata-se de excertos encomendados pelo imperador bizantino Constantino Porfirogeneto (séc. X), sob o título Sobre Virtude e Vício. A outra metade dos fragmentos, não traduzidos nesta publicação, são do Codex Escorialensis. ${ }^{1}$

No conjunto dos fragmentos que aqui se traduzem, é possível identificar uma unidade da narrativa, ${ }^{2}$ como é de se esperar de excertos selecionados a partir do filtro temático "virtude e vício". Os quinze capítulos desses fragmentos formam um todo coeso, ${ }^{3}$ organizado cronologicamente, de acordo com as experiências e os feitos de Augusto durante sua infância e juventude. Nicolau discorre sobre o nascimento e linhagem de Augusto; sua aparência deslumbrante; o cuidado dos pais para com ele; a iniciação às atividades da vida civil na adolescência; a proteção de Júlio César; e a incipiente participação política de Augusto como intercessor junto a César. Apesar de inseridas pelo autor da seleção encomendada por Constantino Porfirogeneto, ${ }^{4}$ as seguintes palavras, ao final do capítulo 15, confirmam que, até ali, temos uma unidade temática já no próprio texto de Nicolau: "Fim da história de Nicolau de Damasco e da vida do jovem César".

Este é, porém, um fim parcial, uma vez que, abstraídas essas palavras, temos a continuidade da vida até o capítulo 31, como já foi dito. O fato que atua como marco divisor das duas porções da narrativa é a morte de Júlio César: antes dela, Nicolau apresenta o jovem Augusto ainda à sombra política de César (capítulos de 1 a 15), descrevendo seu comportamento como extraordinariamente exemplar e como que moldado para a liderança que o espera no futuro; logo após a morte do ditador, Augusto obriga-se a iniciar propriamente sua maioridade política para vingar o tio morto, o que culminará em sua ascensão política imediata (capítulos de 16 a 31). 
Nicolau (nascido em 64 a.C.) viveu na mesma época em que Augusto (nascido em 63 a.C.) e privou de relaçóes

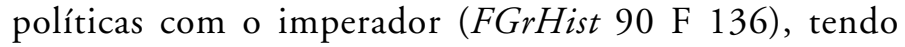
desfrutado do ambiente fértil e estimulante para as artes em geral da Roma imperial. Não é de estranhar, portanto, que A Vida de Augusto de Nicolau, como se verá, seja um panegírico, um encômio a Augusto, retomando a tradição de Agesilau, de Xenofonte (séc. V a.C.), e de Evágoras, de Isócrates (séc. IV a.C.), ainda que, com relação a estes, se distinga por tratar de líder político ainda vivo na época do biógrafo. Os primeiros capítulos apresentam o êthos do biografado, destacando-o com superlativos e qualidades especiais que já informam o tópos da exemplaridade:

F 125 (1): tendo alcançado o mais alto grau de poder e inteligência, este homem governou sobre o maior número de pessoas de que se tem memória

F 126 (2): De fato, sobre esse homem é possível mostrar quão grande era o poder tanto de sua inteligência quanto de sua virtude

Seguindo a orientação peripatética de Nicolau, a seleção de fatos que compõem a Vida de Augusto prioriza uma dicotomia do tipo virtude/vício, ${ }^{6}$ em que a virtude aparece sempre como característica constante do biografado, em contraponto eventual a vícios de outrem. Talvez por isso a obra tenha sido utilizada para a coleção de excertos de Constantino. Nesse sentido, destoa consideravelmente da biografia homônima de Suetônio, em que há espaço para a descrição de atos violentos de Augusto, bem como referência ao ódio que muitos lhe nutriam (cf. Vida de Augusto, Suetônio, 17-19). Quanto à aderência de Nicolau às ideias peripatéticas, Momigliano considera o aristotelismo de Nicolau superficial, ainda que este descreva as qualidades de Augusto segundo a ética aristotélica. ${ }^{7}$ Com efeito, o excessivo tom laudatório permeia o texto do início ao fim, o que compromete qualquer princípio de moderação e sensatez, tão caras ao Perípato, e põe sob suspeição a intenção inicialmente declarada por Nicolau de dar a seu leitor a verdade (cf. F 126: E eu mesmo narrarei seus feitos, a partir dos quais será possivel a todos conhecer a verdade).
6. Momigliano menciona o interesse dos Peripatéticos em selecionar anedotas um componente tradicional do gênero bios - para ilustrar, em monografias, as virtudes e vícios de certos indivíduos (MOMIGLIANO, 1993, p. 69).

7. MOMIGLIANO, 1993, p. 86. 
8. GOODMAN, 1997, p. 38.

9. HALL, 1923, p. iii.

10. Particular ênfase quanto a esse aspecto encontra-se em suas notas aos capítulos 10-12 (HALL, 1923 , p. 80 (12 n.1)

11. HALL, 1923 , p. 80 (12 n.1). Essa conclusão pode corresponder, realmente, à realidade, se lembrarmos que moedas com a imagem de Augusto apresentavam-no com aparência mais do que humana e enfatizavam o nome César e a origem divina de seu pai, reconhecida formalmente pelo senado e pelo povo romano em 42 a.C. (GOODMAN, 1997, p. 36).

12. MOMIGLIANO, 1993 , p. 86.

13. A sistematização dessas diversas classificaçōes, assim como uma crítica às suas limitaçôes, encontra-se em IPIRANGA JÚNIOR, no artigo "Fragmentos e tópoi biográficos nos séc. V e IV a.C.", que integra o presente dossiê.

\section{Cf. IPIRANGA} JÚNIOR, "Fragmentos e tópoi biográficos nos séc. V e IV a.C.”, neste dossiê.
Cogita-se que não só muitas informações da Vida de Augusto de Nicolau mas também o tom adotado por ele sejam tributários das memórias de Augusto, publicadas em 25 a.C., ${ }^{8}$ às quais o biógrafo teria tido acesso. Hall considera que elas tenham sido a fonte principal, senão a única, dos capítulos de 1 a $18,{ }^{9}$ e, comparando algumas informações do texto com outras fontes, conclui que determinados fatos mencionados por Nicolau só podem ter sido extraídos das memórias de Augusto, além do próprio viés extremamente encomiástico da biografia. ${ }^{10}$ Quanto a esse aspecto, Hall sugere que Nicolau pode ter simplesmente se servido das mesmas palavras encontradas nas memórias de Auguto e invoca os termos nada modestos da inscrição da Res Gestae Divi Augusti como possível evidência por comparação. ${ }^{11}$

Por outro lado, considerada por Momigliano o melhor exemplar preservado de biografias de reis da tradição helenística, ${ }^{12}$ a Vida de Augusto, de Nicolau, revela a recorrência de tópoi tradicionais na constituição do gênero bios. Presta-se, com efeito, a diversas classificações propostas por estudiosos do gênero: biografia peripatética, com apresentação cronológica dos fatos e foco nas virtudes morais do biografado (Leo, Klaus Berger); encômio de líder político (Wehrli); biografia contemporânea-definida (Smith). ${ }^{13}$ Seguem alguns exemplos de tópoi discursivos biográficos encontrados no bios de Nicolau, na esteira do que propóe Ipiranga Júnior para uma classificação mais abrangente dos elementos constituintes do gênero bios: ${ }^{14}$

b) tópos relativo a aspectos ou fases da existência e.g., ascendência/linhagem/origem e nascimento e circunstâncias da infância:

F 126 (2): Por certo, seu pai era Caio Otávio, homem de estatuto senatorial. Seus antepassados, célebres por causa de sua riqueza e seu senso de justiça, legaram-no seu dinheiro quando ficou órfāo. Porém, tendo-lhe sido indicados tutores, estes o roubaram.

F 127 (3): Quando morreu sua avó, passou a ser criado pela mãe, Ácia, e pelo marido desta, Lúcio Filipe, que era descendente dos que haviam subjugado Filipe, o Macedônio. 
d) tópos referente a contextos socioculturais - e.g., o estatuto do herói (filósofo, político, general, homem santo etc.):

F 127 (4): Admirado pelo povo inteiro, pela sua aparência nobre e pelo seu esplendor, [começou a fazer sacrifícios aos deuses], foi inscrito para concorrer a pontífice no lugar de Lúcio Domício, que havia morrido. E o povo, com muito entusiasmo, elegeu-o para essa função. Ele, embelecido com a nova toga e, ao mesmo tempo, com a mais bela honraria, fazia sacrifícios <aos deuses $>$.

e) tópos concernente à paideia - e.g., treino físico e mental e exercícios ascéticos e ligados ao cuidado de si:

F 127 (3): Pois ele exercitava tanto o espírito com as mais belas práticas quanto o corpo com exercícios nobres e de guerra, e mais rápido do que seus mestres ele demonstrava em ações o que tinha aprendido, de modo que com isso também angariava muito prestígio em sua pátria.

F 128 (13): nem partilhava da companhia de jovens embriagados; nem se demorava muito tempo em banquetes depois do entardecer; nem, por outro lado, jantava antes das dez horas, exceto na casa de César ou de Filipe ou de Marcelo, casado com sua irmã - homem muito prudente e dentre os Romanos de mais nobre ascendência.

f) tópos diegético - e.g., narrativas de combate e de estratégias de guerra:

F 127 (10): Em seguida, partiu do solo pátrio para a expedição militar, de acordo com as ordens do tio. Pois era assim que chamava a César. E, quando muitos homens ficaram ansiosos para partir com ele por causa da grande expectativa que havia sobre si, após ter afastado a todos, mesmo a sua própria mãe, escolheu os mais rápidos e mais fortes de seus servos e começou a comandar a marcha impacientemente; com incrível velocidade, percorreu o longo caminho e chegou próximo de onde estava César, que já tinha concluído a guerra inteira em sete meses.

A importância do texto de Nicolau para a tradição biográfica, portanto, em que pese seu tom repetitivo de louvor a Augusto, está justamente em ser um dos representantes mais antigos e talvez mais bem acabados, com fragmentos de considerável extensão, do gênero bios, particularmente de orientação peripatética. Sua influência 
15. Momigliano cogita mesmo ter Nicolau influenciado Plutarco em suas técnicas biográficas (MOMIGLIANO, 1993,

$$
\text { p. 86). }
$$

16. O título que antecede o fragmento 125 é "Sobre a vida de César, o Augusto, e sua educação". Optou-se aqui pela denominação tradicional e sintética "A vida de Augusto", frequentemente utilizada na bibliografia especializada.

17. Segundo Hall, esta nota entre parênteses é de quem recolheu os excertos para Constantino

Porfirogeneto (HALL, 1923 , p. p. 76 (1 n.5). em autores posteriores é, sem dúvida, uma via de pesquisa bastante frutífera, talvez pouco explorada ainda pelo fato de haver tão poucas traduções disponíveis em línguas modernas, tanto de sua autobiografia quanto de sua biografia de Augusto. ${ }^{15}$ Espera-se que a tradução a seguir possa colaborar para minimizar esse problema.

\section{A Vida de Augusto ${ }^{16}$}

F 125. Sobre a primeira fase da educação de César, o Augusto.

1. Por imposição de sua honra, assim o denominaram os homens; espalhados por ilhas e continentes, com templos e sacrifícios o veneram, bem como por cidades e tribos, em retribuição à magnificência de sua virtude e a seus bons serviços para com eles. Pois, tendo alcançado o mais alto grau de poder e inteligência, este homem governou sobre o maior número de pessoas de que se tem memória, e tornou muito mais distantes as fronteiras da dominação dos Romanos, e deixou em situação extremamente estável não somente os povos de Helenos e Bárbaros, mas também seus desígnios. Primeiro com armas, depois igualmente sem armas, atraindo homens voluntários, por destacar-se por sua generosidade, ele convenceu-os a obedecer-lhe. Quanto a esses homens, antes nem seus nomes eram conhecidos, nem a ninguém tinham sido subordinados, segundo se tem memória, pois foi ele quem subjugou todos quantos habitam às margens do rio Reno e além do mar Jônico e dos povos da Ilíria - chamam-nos Panônios e Dacos. (Veja a obra Sobre os Bravos Feitos). ${ }^{17}$

\section{F 126}

2. De fato, sobre esse homem é possível mostrar quão grande era o poder tanto de sua inteligência quanto de sua virtude - por um lado, com base no governo que exerceu em sua pátria, e, por outro, em face de seus serviços como general em grandes guerras tanto locais quanto com outros povos, objeto de debate que se propõe para homens falarem e escreverem, de modo que possam obter renome com belas obras. E eu mesmo narrarei seus feitos, a partir dos quais será possível a todos conhecer a verdade. Mas antes farei uma exposição sobre seu nascimento e linhagem, e sobre seus pais, de quem descendia, e sobre a criação e educação de que usufruiu desde pequeno para tornar-se um tal homem. Por certo, seu pai era Caio Otávio, homem de estatuto senatorial. 
Seus antepassados, célebres por causa de sua riqueza e seu senso de justiça, legaram-no seu dinheiro quando ficou órfão. Porém, tendo-lhe sido indicados tutores, estes o roubaram. Ele, evitando processá-los em justa causa, contentava-se com os bens restantes.

\section{F 127}

3. Augusto, aos nove anos de idade aproximadamente, propiciou aos Romanos um espetáculo nada desprezível, ao mostrar uma habilidade superior de sua natureza em tal idade: discursou para uma grande multidão, provocando muitos aplausos entre os homens. Quando morreu sua avó, passou a ser criado pela mãe, Ácia, e pelo marido desta, Lúcio Filipe, que era descendente dos que haviam subjugado Filipe, o Macedônio. Junto a Filipe, Augusto, como se fosse criado pelo pai, dava sinais promissores e revelava-se altamente apreciado por seus companheiros, os meninos bem nascidos. Reuniam-se com ele em grande número - e não poucos também dos mais jovens que tinham esperança de envolver-se com política. Acompanhavam-no diariamente todos - rapazes, homens, meninos de sua idade -, quer quando ele fosse praticar exercícios equestres, fora da cidade, quer quando fosse visitar seus parentes ou quaisquer outras pessoas. Pois ele exercitava tanto o espírito com as mais belas práticas quanto o corpo com exercícios nobres e de guerra, e mais rápido do que seus mestres ele demonstrava em ações o que tinha aprendido, de modo que com isso também angariava muito prestígio em sua pátria. Cuidavam dele ambos, sua mãe e o marido desta, Filipe, todo dia informando-se, junto aos mestres e tutores que acompanhavam o menino, do que tinha feito ou aonde tinha ido ou como tinha passado o tempo e com quem tinha estado.

4. Durante o tumulto que tomou conta da cidade ( 49 a.C.) ${ }^{18}$ sua mãe Ácia e Filipe enviaram Augusto secretamente para um dos sítios de seu pai na área rural. Augusto começou a frequentar o Fórum quando tinha em torno de quatorze anos, de modo a deixar de lado já a toga pretexta, ${ }^{19}$ e a usar a toga sem adereços, marca de seu registro como homem adulto. Admirado pelo povo inteiro, pela sua aparência nobre e pelo seu esplendor, [começou a fazer sacrifícios aos deuses], ${ }^{20}$ foi inscrito para concorrer a pontífice no lugar de Lúcio Domício, que havia morrido. E o povo, com muito entusiasmo, elegeu-o para essa função. Ele, embelecido com a nova toga e, ao mesmo tempo, com a mais bela honraria, fazia sacrifícios <aos deuses> ${ }^{21}$ Entretanto, apesar de registrado como homem adulto de acordo com a lei, sua mãe não o deixava sair para fora da porta de casa, salvo para onde ele costumasse ir antes, quando era menino, e o obrigava a manter o
18. Guerra civil provocada por Júlio César em 49 a.C. (cf. $O C D$, p. 1326).

19. Toga branca com barra de cor púrpura usada pelos jovens de famílias patrícias.

20. Texto corrompido.

21. Texto restaurado. 
22. Para elucidar a passagem, Hall cita Valesius sobre o costume de jovens e senadores vestirem-se com vestes orientais no tempo de Cícero (HALL, 1923, p. 77,4 n.7).

23. Como prefeito da cidade, informação que, segundo Hall, parece certa somente em Nicolau, entre outras fontes sobre o fato, e é confirmada, indiretamente, por Estrabão (5, C, 229) e Dio (49, 42), que afirmam que o costume de indicar jovens para essa função foi mantido por Augusto

(HALL, 1923, p. 78, 5 n.2). Augusto teria na ocasião dezesseis anos. mesmo modo de vida ali e a ficar no mesmo quarto de criança. Era homem adulto somente segundo a lei; quanto ao resto, era tratado como se fosse uma criança. E nem um detalhe de sua vestimenta ele alterara, mas continuava sempre a usar as vestes romanas. ${ }^{22}$

5. E costumava ir aos templos nos dias habituais à noite, por causa de sua beleza, porque enlouquecia muitas mulheres com sua bela aparência e com o esplendor de sua linhagem. Mas, quando era alvo de desígnios femininos, não parecia, de forma alguma, fácil de seduzir: por um lado, sua mãe afastava-o de tais circunstâncias, porque o vigiava e não o deixava ir a lugar algum; por outro, porque ele mesmo estava já cauteloso, por estar ficando mais velho. Durante o festival latino, quando também os cônsules deviam subir ao monte Alba por causa dos sacrifícios tradicionais, e os sacerdotes sucediam-nos na jurisdição, Augusto sentou-se à tribuna, no centro do Fórum. ${ }^{23} \mathrm{E}$ vários homens começaram a se aproximar dele por causa da jurisdição; muitos, porém, iam também sem motivo algum, apenas para contemplar o jovem. Pois era digno de ser contemplado por todos. E, sobretudo nessa ocasião, superou-se em honra e majestade.

6. Quando César já tinha subjugado os inimigos na Europa, vencido também Pompeu na Macedônia, ocupado o Egito, e saía da Síria e do Ponto Euxino com a intenção de avançar até a Líbia, para conquistar as demais regiōes rebeladas durante a guerra, o jovem César desejou juntar-se a ele na campanha militar, a fim de que também se tornasse experiente em trabalhos de guerra; mas, ao perceber que Ácia, sua mãe, se opunha a isso, aquietouse sem nada lhe contestar. Da mesma forma, César, o mais velho, por afeição a ele, claramente ainda não queria que ele fosse para a guerra, para que não negligenciasse toda a sua condição física, ao mudar os hábitos de vida de um corpo fraco. Era por isso que Augusto era dispensado das campanhas militares.

7. Quando César, porém, tendo obtido sucesso também naquela guerra, voltou a Roma, após ter perdoado pouquíssimos homens dos que haviam sucumbido como prisioneiros, por não não terem aprendido a agir com moderação nas guerras precedentes, aconteceu o seguinte. César, o jovem, tinha relações pessoais de alto grau e amizade com Agripa, tanto por terem sido educados no mesmo lugar, quanto por serem ótimos companheiros. $\mathrm{O}$ irmão de Agripa estava com Cato, porque lhe respeitava muito, por amizade, e porque juntos tinham participado da guerra da Líbia, quando então fora tomado como prisioneiro. Augusto queria que ele fosse perdoado, embora não tivesse pedido nada a César; hesitava, por vergonha e também porque via como César 
agia em relação àqueles que haviam sido capturados naquela guerra. Então certa vez, criando coragem, fez o pedido e foi bem sucedido. Por causa disso, Augusto ficou muito contente com o fato de ter salvo o irmão de seu amigo. E foi, de fato, elogiado pelos outros, por ter dispensado sua atenção e ter intercedido, em primeiro lugar, para a salvação de um amigo. ${ }^{24}$

8. Logo em seguida, César começou a conduzir as comitivas de honra pelo triunfo na guerra da Líbia e nas demais guerras que travara. E, já tendo adotado como filho ao jovem César, o que este era, de certo modo, também por natureza, por ser de família muito próxima, ordenou-lhe seguir em seu próprio carro de guerra, e enfeitou-o com adereços de general, como se já tivesse sido seu companheiro na guerra. Da mesma forma, nos sacrifícios e procissões para os templos divinos, colocava-o mais perto de si e ordenava aos demais ceder espaço a Augusto. César já recebia honras de imperador, que eram as mais importantes segundo o costume dos Romanos, e era admirado na pátria. O jovem, estando com ele nos teatros e em festas, e vendo que César conversava com ele de modo gentil tal como com um filho, e já com um pouco mais de coragem, quando muitos amigos e cidadãos começaram a lhe pedir que intercedesse junto àquele para obterem, cada um, o que necessitassem, Augusto, observando as boas oportunidades, com todo o respeito, fazia as solicitações e tinha êxito em seus pedidos. E tornou-se bastante estimado por muitos de seus conterrâneos, pois tomava cuidado para não invocar César abruptamente e em momentos inoportunos. E não poucas eram as centelhas do brilho de generosidade e inteligência natural que ele exibia.

9. César, desejando que Augusto se tornasse também experiente na função de presidir a exibição de coros públicos - pois havia dois teatros, o Romano, do qual ele próprio se encarregava e cuidava, e o outro, o Helênico -, confiou-lhe a função com relação a este teatro. E Augusto, empenhando-se seriamente para demonstrar zelo e generosidade, em dias longos e muito quentes, sem afastar-se do posto para lugar algum até que acabasse o espetáculo, caiu doente, por ser jovem e não ter o hábito do trabalho cansativo. Como estava mal, todos ficaram temerosos, angustiados com o fato de que uma tal constituição como a dele pudesse sofrer algum infortúnio - e de todos principalmente César. Por isso, todos os dias animava-o, indo ele mesmo até Augusto ou enviando-lhe amigos e não permitindo que médicos se afastassem dele. Um certo dia, enquanto César jantava, alguém anunciou-lhe que Augusto estava debilitado e que seu estado era
24. Hall, com base em várias outras fontes, ressalta o exagero de Nicolau nessa passagem, já que César, em circunstâncias similares, permitia a cada um de seus subordinados garantir a liberdade de um prisioneiro (cf. HALL, 1923, p. 78, 7 n. 2) 
25. Pompeu havia sido derrotado por César em Farsalo, em 48 a.C. (cf. $O C D$, p. 1216). grave. César deu um pulo e foi descalço lá onde o doente era tratado; começou a rogar aos médicos muito emocionado, tomado de angústia, e sentou-se ele mesmo junto ao enfermo. Após reanimá-lo, César encheu-se de alegria.

10. Quando Augusto tinha se recuperado da doença e escapado do perigo, ainda com o corpo frágil, foi necessário que César partisse em campanha militar em que antes pensara levar consigo também o jovem. Mas este não estava em condições para tanto, por causa da doença que lhe tinha acometido. Assim, César, tendo deixado muitos oficiais seus junto a Augusto, para que este fosse mantido sob cuidados, em regime bem regrado, deulhes ordens de que, caso Augusto se fortalecesse, escoltassem-no até ele; e foi para a guerra. Pois o filho mais velho de Pompeu, o Grande, como tivesse reunido grande exército em pouco tempo contra a expectativa de todos, planejava socorrer o pai e lutar para reverter a derrota deste, ${ }^{25}$ se possível. Augusto, que havia sido deixado em Roma, em primeiro lugar, cuidou de deixar seu corpo em pleno vigor, e rápido recobrou sua força física. Em seguida, partiu do solo pátrio para a expedição militar, de acordo com as ordens do tio. Pois era assim que chamava a César. E, quando muitos homens ficaram ansiosos para partir com ele por causa da grande expectativa que havia sobre si, após ter afastado a todos, mesmo a sua própria mãe, escolheu os mais rápidos e mais fortes de seus servos e começou a comandar a marcha impacientemente; com incrível velocidade, percorreu o longo caminho e chegou próximo de onde estava César, que já tinha concluído a guerra inteira em sete meses.

11. Ao chegar, porém, a Tarraco, mostrou insegurança para entrar em tamanho tumulto de guerra. Como não encontrara César ali, ficava mais aflito e em perigo. Então, foi para a Ibéria e encontrou César perto da cidade de Calpe. E este, abraçando Augusto como a um filho, porque o tinha deixado doente e o via agora inesperadamente a salvo de tantos inimigos e piratas, saudava-o alegremente. Não o deixava ir a lugar algum e mantinha-o como conviva. César elogiava tanto sua disciplina quanto seu esforço, porque fora o primeiro a chegar dos que haviam partido de Roma; e dedicava-lhe atenção, enquanto ele conversava, para interrogálo sobre muitos assuntos, pondo seu raciocínio à prova. E, vendo que era direto, perspicaz e sucinto e que lhe respondia da forma mais adequada possível, afeiçoava-se-lhe e alegrava-se ainda mais.

Depois, foi preciso que navegassem para Cartago Nova. E, tendo sido ordenado a Augusto que embarcasse junto a César, na mesma nau, com cinco escravos, ele, por amizade, fez embarcar também três 
companheiros seus além dos escravos; e temia que César, ao saber disso, o reprovasse. Mas aconteceu o contrário. Pois César alegrou-se com o fato de Augusto tratar seus amigos com afeto e elogiou-o por sempre querer ter junto de si homens que seriam obervadores de tudo e que se preocupariam com a excelência; e por ele já dedicar, em sua pátria, não pouca atenção a ter uma reputação valiosa.

12. César chegou a Cartago Nova a fim de encontrar-se com quem dele necessitasse. E muitos dirigiam-se a ele - uns, por causa de sua jurisdição, para tratar de questôes em disputa com alguns cidadãos; outros, por causa da administração da cidade; e outros, para que pudessem receber os prêmios de guerra por seus atos de coragem. Com estes se encontrou, e um grande número de líderes de outros grupos reuniu-se com ele. Buscam auxílio junto a Augusto os habitantes de Jacinto, porque tinham muitas acusações contra si e precisavam de ajuda. Este os protegeu e, tendo ponderado com César muito bem e abertamente, livrou-os das acusaçôes e mandouos para casa alegres, celebrando-o em cantos para que todos ouvissem e chamando-o de salvador. Dali em diante, muitos corriam a ele, necessitados de proteção, para os quais passava a ser de grande valia: de uns removia as acusações; para outros conseguia recompensas; e outros ainda conduzia a cargos do governo. E todos comentavam sua cortesia, generosidade e ponderação nos pronunciamentos. O próprio César ${ }^{* * * 26}$

\section{F 128}

13. ${ }^{* * *}$ de prata, ${ }^{27}$ de acordo com os costumes ancestrais; nem partilhava da companhia de jovens embriagados; nem se demorava muito tempo em banquetes depois do entardecer; nem, por outro lado, jantava antes de dez horas, exceto na casa de César ou de Filipe ou de Marcelo, casado com sua irmã homem muito prudente e dentre os Romanos de mais nobre ascendência. Pudor - que alguém de tal idade deveria considerar conveniente, pelo fato de ter sido concedido a essa virtude, pela natureza, lugar prioritário em relação às outras - muito claramente e também em ações Augusto manifestava, durante toda a sua vida. De fato, especialmente por causa disso, César o tinha em alta estima - e não, como muitos pensam, somente por causa de seu parentesco. Tinha mesmo antes decidido declará-lo como filho, mas, temendo que se tornasse arrogante com a expectativa de tamanha sorte - o que é do agrado dos que são criados em ambiente próspero - e que se esquecesse completamente da virtude e do modo de vida disciplinado, ocultou sua decisão. Inscreveu-o, porém, como filho em seu testamento, pois não
26. Lacuna no texto.

27. Adoto aqui a leitura restaurada de Mueller: $<a r>$ guroû. 
28. Texto corrompido.

29Texto restaurado. tinha filhos do sexo masculino, e declarou-o herdeiro de toda a fortuna. Mas deixou uma quarta parte do dinheiro com outros amigos e concidadãos, o que mais tarde ficou manifesto.

14. Augusto pediu a César que lhe concedesse retornar à pátria para ver sua mãe; quando César deu-lhe permissão, partiu. Enquanto Augusto chegava, não longe de Roma, a Janículo, encontrou-o, com um grande número de pessoas, o chamado filho de Caio Mário, que estava ansioso para inscrever-se como membro da família de Augusto e tinha levado consigo algumas mulheres parentes de César, que davam testemunho de sua nobre origem. Contudo, não persuadiu nem a Ácia, nem a irmã desta, a darem uma falsa declaração sobre sua família. Pois [a família $]^{28}$ de César era relacionada $<$ à ${ }^{29}$ de Mário, mas de fato não havia parentesco algum com aquele jovem. Ele, então, tendo ido atrás do jovem César com uma grande multidão, esforçava-se por conseguir também a confiança deste para sua inscrição como membro daquela família. E muito apoio havia dos cidadãos que estavam com ele, por estarem persuadidos de que ele era filho de Mário. Augusto, em terrível dificuldade a respeito da situação, avaliava o que devia fazer. Pois cumprimentá-lo como parente - que ele não sabia de onde era e cujo parentesco nem sua mãe tinha testemunhado - era difícil, assim como repelir o jovem e a multidão de cidadãos que o acompanhava. Por outro lado, Augusto, tomado de pudor, estava muito constrangido. Assim, afastando o homem, respondeu gentilmente dizendo que César era o líder de sua família e dirigente de toda a pátria e do governo dos Romanos; que o jovem devia ir até César e dar-lhe evidências do parentesco; e que, se o persuadisse, ele teria imediatamente também outros familiares persuadidos; que, do contrário, nenhuma ligação haveria da parte deles com ele; e que, nesse ínterim, antes de César decidir sobre isso, o jovem não se aproximasse dele, Augusto, para buscar uma prova legal de parentesco. Após ter-lhe respondido assim sensatamente, os presentes o louvaram; mas o jovem, ainda assim, o seguiu até a sua casa.

15a). Quando chegou a Roma, alojou-se perto da casa de Filipe e de sua mãe. E não fazia nada sem os dois, salvo se alguma vez desejasse banquetear-se com alguns dos rapazes de sua idade. Mas isso era raro. Enquanto estava na cidade, o senado declarou-o patrício.

\section{F 129}

15 b) O jovem César não bebia e vivia com moderação. Também um outro aspecto extraordinário seus amigos sabiam sobre ele: durante um ano inteiro - nessa idade em que os jovens estão no 
seu máximo vigor, sobretudo os abastados -, ele mantivera abstinência dos prazeres sexuais, preocupando-se, nesse período, com sua voz e força física.

Fim da história de Nicolau de Damasco e da vida do jovem César.

\section{REFERÊNCIAS BIBLIOGRÁFICAS}

GOODMAN, Martin. The Roman World. 44BC-AD180. London and New York: Routledge, 1997.

HALL, Clayton Morris. Nicolaus of Damascus' Life of Augustus. A Historical Commentary Embodying a Translation. Smyth College Classical Studies, IV, 1923, iii-iv, 1-97.

HORNBLOWER, Simon; SPAWFORTH, Antony (ed.). The Oxford Classical Dictionary (OCD). Oxford: Oxford University Press, 2003.

IPIRANGA JÚNIOR, Pedro. Fragmentos e tópoi biográficos nos séc. V e IV a.C. Clássica, presente dossiê.

JACOBY, Felix. Die Fragmente der Griechischen Historiker (FGrHist). Leiden: E. J. Brill, 1986, p. 324-430.

MOMIGLIANO, Arnaldo. The Development of Greek Biography. Cambridge, London: Harvard University Press, 1993.

PRIETO, Maria Helena de Teves Costa Ureña; PRIETO, João Maria de Teves Costa Ureña; PENA, Abel de Nascimento. Indices de Nomes Próprios Gregos e Latinos. Coimbra: Fundação Calouste Gulbenkian, Junta Nacional de Investigação Científica e Tecnológica, 1993.

SUETONIUS. The Lives of the Twelve Caesars; An English Translation, Augmented with the Biographies of Contemporary Statesmen, Orators, Poets, and Other Associates. Suetonius. Publishing Editor. J. Eugene Reed. Alexander Thomson. Philadelphia: Gebbie \& Co., 1889.

Enviado em janeiro de 2014 Aprovado em abril de 2014. 
